\title{
Development of Revenue Model for Optimum Gas Distribution and Utilisation in Nigeria
}

\author{
Kenneth Nduka, Ubanozie Julian Obibuike, Mathew Udechukwu, Chioma Deborah Mbakaogu, \\ Anthony Chemazu Igbojionu, Stanley Toochukwu Ekwueme
}

Department of Petroleum Engineering, Federal University of Technology, Owerri, Nigeria

Email address:

stanleyekwueme@yahoo.com (S.T. Ekwueme)

\section{To cite this article:}

Kenneth Nduka, Ubanozie Julian Obibuike, Mathew Udechukwu, Chioma Deborah Mbakaogu, Anthony Chemazu Igbojionu, Stanley Toochukwu Ekwueme. Development of Revenue Model for Optimum Gas Distribution and Utilisation in Nigeria. International Journal of Oil, Gas and Coal Engineering. Vol. 8, No. 6, 2020, pp. 143-150. doi: 10.11648/j.ogce.20200806.14

Received: September 21, 2020; Accepted: October 6, 2020; Published: November 16, 2020

\begin{abstract}
The emergence of gas projects have increased the demand for natural gas. Producers of natural gas are faced with the challenge of gas distribution to users. At this point, in order to maintain demand and supply, a model is required to determine optimum distribution of gas. In this paper, models are developed for optimum gas distribution and utilisation in Nigeria. The models seek to evaluate the monetary returns accruable from the utilisation of gas resources produced in Nigeria for domestic uses. Many outlets were suggested for domestic utilisation of gas produced in Nigeria. These gas utilisation and monetization outlets were proved to have viability and competitive advantage when compared with the sales of the gas abroad. The domestic gas supply revenue formula was formulated by considering the quantity of gas each gas producer will produce, the demand of the gas locally, the price stipulated for the gas in order to ensure profitability when sold locally, the penalty price for companies willing to flare and not supply their gas, the gas deficiency price etc. The revenue formula helps the government and gas producers to determine the extent of financial returns accruable from the sale of gas for domestic utilisation. The Model is sufficient to help the government make necessary decisions and plans as regarding domestic gas aggregation in Nigeria.
\end{abstract}

Keywords: Revenue, Gas Utilisation, Gas Distribution, Model

\section{Introduction}

Following Nigeria's gas reserves currently estimated at 202 TCF (trillion cubic feet), the nation's gas sector has proven to have the potential of being a key player in the emergent global natural gas market and locally in the development of domestic gas projects. Furthermore, Nigeria population of close to 200 million people sets a potential market opportunity for the Nigeria gas. Unfortunately, even with this huge gas reserve, not much has been accomplished with respect of the effective exploitation and utilization of this abundant natural gas reserve [1].

Natural gas production in Nigeria has been via two means: as associated gas when the gas comes in contact with the oil during oil production as non-associated gas when specific gas wells are drilled for the sole reason of gas production. Unlike oil, gas markets are volatile and the technology needed for gas extraction and processing are more complex, costly and sensitive to changes. Previously, producer's preferred not to invest in gas development and monetisation because they saw oil as far more profitable venture than natural gas and because of this, they flare their associated gas. With the recent technological breakthroughs in gas technology and the global initiative on fossil fuel pollution reduction, much emphasis have been shifted from oil to natural gas. This is partly because natural gas is more abundant than oil and also due to its lower emission characteristics and lower carbon potentials. With this rising interest in natural gas, demand for it has increased both international and locally [2].

Having highlighted the prospects of natural gas to modern economies, it is pertinent to understand the factors that creates distortions and imbalances in the availability of this resource. Gas producers in Nigeria are faced with the choice of utilising their gas, selling the gas locally for domestic utilization or selling it abroad at the international markets. Gas exports provides higher revenue both to gas producers and the government. The government get their share through taxes, royalties, dividends and equity stake. The gas 
producers make more profit from the sale of gas abroad than locally. This is because gas sells at higher price at the international market than at the local markets. This is creating an anomaly in Nigeria where there is now a significant shortfall in the availability of gas for domestic utilization [3, 4]. This has stalled the development of domestic gas projects and impacted negatively on the country which if unchecked may result in Nigeria supporting the development of the economies of the industrialized nations at the expense of its own economy.

Therefore, it is essential to map out strategies for exploiting the domestic markets and ensure industrialization of the country through domestic utilization of natural gas $[5,6]$.

\section{Investment Opportunities in the Nigerian Gas Sector}

Natural gas utilization entails devising a strategy for converting natural gas from the wellhead to several market options for economic and environmental benefits.

Ogwo [7] proved that the prospects for the growth of the gas industry are enormous when viewed from the various industrial and commercial consumers that need to be served and the potential local market available for chemicals derived from natural gas, which are currently imported. Investment options include:

\subsection{Independent Power Plants}

The power sector is key to any emerging economy attracting investors and encouraging local productivity. About $75 \%$ of Nigeria's population has no access to electricity [8]. Natural gas which is being flared can provide a cushion in power generation, and it can be supplemented by other renewable energies. Government is encouraging JV and PSC multinational oil companies operating in Nigeria to embark on Independent Power Plants (IPP), as part of its power sector reform. The reform act reviewed the generation, transmission and distribution of electricity in the country to improve its performance. The IPPs will not only boost electricity supply but also provide necessary infrastructural support for economic growth of JVs / PSC companies [9]. This would give guarantee additional revenue to participating companies. The IPPs will further strengthen the oil companies' social responsibility in the local economy as well as protect the environment through environmentally sustainable operations and industry best practices [10].

\subsection{Natural Gas Liquids}

Natural Gas Liquids could be recovered from gas streams that are richer in heavier hydrocarbons (ethane, propane, butane, pentane, etc.) especially $\mathrm{AG}$ which is ordinarily flared. These liquids have high market values and find applications either in their raw form solvents, feed stocks (for production of various chemicals) and liquid fuels, they can be fractionated into their components viz. Liquefied Petroleum Gas (LPG), Cooking Gas, Natural Gasoline and various
Special Boiling Point (SBP) solvents. Opportunities abound for interested third parties or private sector to invest in the establishment of NGLs extraction plants to recover Natural Gas Liquids from major supply schemes [11].

\subsection{Gas-to-Liquid (GTL)}

GTL is the conversion of gas to liquid by a chemical processes called Fisher - Tropsch (FT). The liquid produced in this process remains the end product which is quite unlike the LNG that the liquid will be allowed to expand under temperature rise to form gas. These include the Escravos gas to liquids with a capacity of $34 \mathrm{MMbbl} / \mathrm{yr}$ the Escravos NGL 1,2 , and 3 as well as the Mobil NGL 1 and 2.

Adegoke [12] maintained that in totality, on-going gas transmission programs would entail commercialization of about $1475 \mathrm{mmscf} / \mathrm{d}(80 \%$ for LNG). However, about $\$ 2.5 \mathrm{bn}$ will be required annually in stable investment (upstream and LNG plants) to capture opportunities in gas and power. The private sector therefore has a critical role to play in the realization of this and other projects. With this development in the gas sector as well as transformation in the upstream, it is believed that energy sector-driven initiatives could contribute up to $60 \%$ towards the doubling of the nation's GDP over the next 10 years.

\subsection{Feedstock for Petrochemical Industries}

The petrochemical market is the foundation of many chemicals industry, as it provides the building blocks for most chemical products. For instance, Olefins (Ethylene, propylene, butadiene) and aromatics (benzene, toluene and xylene) are used in end-user markets such as paints, plastics, explosives and fertilizers. Natural gas and natural gas liquids are used to manufacture a gamut of intermediate chemicals and finished products [13].

\subsection{Gas as a Residential Fuel}

A sizable gas market exists in the distribution of natural gas for domestic heating and cooking, and for refrigeration and air conditioning [14]. Natural gas can be used for this purpose in form of Liquefied Petroleum Gas (LPG). Liquefied petroleum gas (LPG) is a term describing a group of hydrocarbon-based gases derived from crude oil and or natural gas. Natural gas purification produces about 55 percent of all LPG, while crude oil refining produces about 45 percent. LPG is mostly propane, butane or a mix of the two. It also includes ethane, ethylene, propylene, butylene, isobutene and isobutylene; these are used primarily as chemical feedstocks rather than fuel [15].

\section{Methods}

We develop formulas for determination of revenue accruable from the domestic gas supply obligation.

\subsection{DGSO Revenue Model Development}

The intension is to maximize the benefits of DGSO and 
increase company's profit. This project, took is a proactive measure enabler, that would ensure the elimination of subjective decisions and enable the optimization of resource allocation and utilization. One of the ways of achieving this was by working out the revenue from DGSO. Revenue can be expressed as the product of the gas price and the volume of gas supplied. It was also considered as a matter of necessity to look into the revenue from gas deficit. This was to guide the gas aggregator in accruing the benefits of DGSO and also to facilitate flare down policy. Revenue from flared gas would also help the gas aggregator to manipulate the DGSO policy thereby ensuring that gas producer do not chose to flare gas instead of meeting up its obligation.

Revenue could be expressed in term of profit percent and also in terms of the price and gas supplied. For simplicity this study considered the latter. The revenue from Domestic gas requirement of company $\mathrm{n}, \mathrm{Rn}$ can take the form

The revenue from Domestic gas requirement of company n,

$$
\mathrm{Rn}=D_{n} \times K_{n}
$$

Revenue from gas supplied by individual company, $R_{n_{i}}$ is

$$
R_{n_{i}}=D_{n_{i}} \times K_{n}
$$

Where $D_{n}$ is Domestic gas requirement of company $\mathrm{n}$ in $\mathrm{MSCF} / \mathrm{yr}$ and $D_{n_{i}}$, the volume of gas supplied by company n, in $\mathrm{MSCF} / \mathrm{yr}$ and $K_{n}$ is the price of gas by company $\mathrm{n}$, in \$MSCF.

The next step was to determine the revenue that would accrue from the gas aggregation. The model formulation for the revenue becomes;

$$
R_{A}=D \times K_{A A}
$$

$R_{A}$ in $\$ / \mathrm{yr}$, is the revenue from total volume of gas demanded $\mathrm{D}$ from all the companies, in $\mathrm{MSCF} / \mathrm{yr}$ and $K_{A A}$, the adjusted aggregated price in $\$ / \mathrm{MSCF}$.

This study considered the penalty for Domestic Gas Supply Obligation, DGSO of defaulters, to ensure compliance by the gas suppliers. This step would also ensure that government do not leap greatly from achieving their estimated revenue generation from gas production.

The Domestic Gas Supply Obligation (requirement) of company $\mathrm{n}$, is $D_{n}$, Actual Volume of gas supplied by the company, $\mathrm{n}$ is $D_{n_{i}}$, then the gas supply deficit, $D_{D_{n}}$ becomes;

$$
D_{D_{n}}=D_{n}-D_{n_{i}}
$$

The total gas supply deficiency $D_{D}$, becomes

$$
D_{D}=\sum_{1}^{\mathrm{n}}\left(D_{n}-D_{n_{i}}\right)
$$

If $D_{D}$ or $D_{D_{n}}$ becomes negative, it means that there was supply deficiency. If zero it means that what was demanded was supplied. TSCF/yr.

The penalty price $\left(K_{P n}\right)$ for company n, not meeting up to the DGSO was made a function of the adjusted aggregated price $\left(K_{A A}\right)$ and the percentage constraints, limiting the company from achieving their obligated gas supply. Therefore, the Penalty price equation becomes,

$$
K_{P_{n}}=K_{A A}(1-\text { constraints } \%)
$$

The constraints could be as a result of the following factors:

1. Fluctuation in price at the international market. If the price of export gas was not stable and leaps more than the OPEC price. Gas producers may work out the economics and chose not to supply at full capacity. And to even choose to pay a penalty instead of achieving their domestic gas obligated supply.

2. The cost of production: The supplier-cost spans through cost of lease acquisition and maintenance, exploration cost, costs of bringing gas up to the production separator, cost of production lines, Facility operational cost, gas processing, storage and shipment to the central hub. If the cost of production per MSCF of gas is greater than the income from gas sells, the gas producers may go back to their economics to see if it is better for possible way out.

3. Market maturity: a situation whereby the gas supplier is not too sure of the rate of return due to market quandary, it may result to laxity in getting up to DGSO.

4. Fiscal terms: funding of gas project is financially enormous and the intricacies associated with fund raising could hinder the company in pooling in their gas quota.

For the specific purpose of providing a numerical solution to the penalty price, the constraint percent need to be quantified. This was done by expressing the constraint percent in terms of quantity of gas supplied $\left(D_{n_{i}}\right)$, to their domestic gas supply obligation $\left(D_{n}\right)$. The penalty price equation becomes;

$$
K_{P_{n}}=K_{A A}\left(1-\frac{D_{n_{i}}}{D_{n}}\right)
$$

This implies that the higher the gas deficit $\left(D_{n}-D_{n_{i}}\right)$, the higher the penalty price. when $D_{n_{i}}=0$, then the penalty price $\left(K_{P_{n}}\right)$ would be the same as the aggregated price $\left(K_{A A}\right)$.

This model therefore provides an incentive to companies that close the gas deficit gap and directly encourages companies to meet up with the DGSO.

The revenue accrues from this exercise, will be the product of the gas deficit and the penalty price. The DGSO penalty revenue for company $\mathrm{n}\left(R_{P_{n}}\right)$ is given as

$$
R_{P_{n}}=K_{P_{n}} \times\left(D_{n}-D_{n_{i}}\right)
$$

\subsection{Revenue from Gas Flare Down}

One of the indirect goals of the gas aggregation and allocation was to encourage gas flare down in Nigeria. If companies respond fully to their gas obligation, gas flare down would be achieved indirectly. If a company flare gas without meeting up to their DGSO, they would be incurring more charges. The first charge would be from Penalty Price 
for not satisfying their obligation. The additional charge would be from Gas Flare Penalty Price. Evaluation of these charges would definitely force operating companies to work out modalities to meet with the DGSO thereby reducing volume of gas flared. The gas flare penalty price has been an issue bothering the government in determining the model for fixing the price. So far there is no defined model for estimated the penalty price for gas flaring. This project shall develop the Gas Flare Penalty price model to suit all government conditions.

The model development for gas flare penalty price for company n, $K_{F P}$ shall put into consideration the aggregated gas price $\left(K_{A A}\right)$, the volume of gas produced by a company $\left(P_{n}\right)$ and the volume of gas flared by a company $\left(F_{n}\right)$.

Factors considered include the following:

1. The penalty price should be zero with no flared gas

2. The gas flare regulated policy should be establish to pull in flexibility

3. The percentage of flared gas if higher than the flare penalty price, then the flare penalty price should be increased so operators would be on their toes to achieve flare down.

4. The gas flare penalty price should not be more than the aggregated gas price, such that it would accommodate the cost of harnessing the gas.

With these factors in consideration, the simplified model becomes

$$
K_{F P_{n}}=K_{A A}\left(\frac{F_{n}}{P_{n}}\right)
$$

This model above assumed, the produced gas was equivalent to the sum of the flared gas and the utilised gas.

The revenue accrues from this exercise, would be the product of the flared gas and the penalty price. The revenue accrued of company n (flare penalty revenue), $R_{F P n}$

$$
R_{F P n}=K_{F P_{n}} \times F_{n}
$$

The actual revenue that accrued from the gas aggregation (is the sum of revenues)=DGSO Penalty Revenue + Flare Penalty Revenue + Revenue from Domestic Gas Supplied

The actual revenue that accrued from the gas aggregation, $R_{A A}$ is

$$
R_{A A}=R_{P_{n}}+R_{F P_{n}}+R_{n_{i}}
$$

\section{Results and Discussion}

The results from the models developed are given and discussed below.

\subsection{Domestic Gas Supply Deficiency, Penalty Price and Revenue}

Analysis of table 1 shows that some company met with their obligation but there was still gas deficiency since bulk of the operators did not meet up.

If we maintain the aggregation price of $\$ 4.985 \mathrm{~B} / \mathrm{TSCF}$; assuming presently that the operating companies are supplying 30 percent of their produce and their DGSO requirement is $2.2 \mathrm{TCF}$ as at year 2010, we shall determine

\begin{tabular}{|c|c|c|c|c|c|c|c|}
\hline Company & $\begin{array}{l}\text { Gas Produced, } \\
P_{n}(\text { TCF } / y r)\end{array}$ & $\begin{array}{l}\text { Domestic gas } \\
\text { supply, } D_{n_{i}} \\
(\mathrm{TCF} / \mathrm{yr})\end{array}$ & $\begin{array}{l}\text { Domestic gas } \\
\text { requirement, } \\
D=2.2 \\
(\mathrm{TCF} / \mathrm{yr})\end{array}$ & $\begin{array}{l}\text { Gas Deficit } \\
D_{n}-D_{I}, \\
(\mathrm{TCF} / \mathrm{yr})\end{array}$ & $\begin{array}{l}\text { Penalty Price } \\
\text { Appreciation } \\
\text { Value, (1-Dni/Dn) }\end{array}$ & $\begin{array}{l}\text { DGSO Gas } \\
\text { Penalty Price, } \\
\text { (\$/TSCF), KA (1- } \\
\text { Dni/Dn) }\end{array}$ & $\begin{array}{l}\text { DGSO Penalty } \\
\text { Revenue, (S/yr), } \\
\text { Kp* (Dn-Di) }\end{array}$ \\
\hline MPNU & 0.0051 & 0.0015 & 0.15666 & 0.15513 & 0.99023 & 4.93631 & 0.76581 \\
\hline $\mathrm{CNL}$ & 0.7780 & 0.2334 & 0.30149 & 0.06809 & 0.22585 & 1.12590 & 0.07666 \\
\hline NAOC & 1.0375 & 0.3112 & 0.31212 & 0.00087 & 0.00280 & 0.01397 & $1.22 \mathrm{E}-05$ \\
\hline ADDAX & 0.2260 & 0.0678 & 0.04678 & -0.02101 & -0.44916 & -2.23908 & 0.04705 \\
\hline NPDC/AENR & 0.0453 & 0.0135 & 0.01555 & 0.00196 & 0.12652 & 0.63070 & 0.00124 \\
\hline SNEPCO & 0.1404 & 0.0421 & 0.07195 & 0.02983 & 0.41464 & 2.06700 & 0.06167 \\
\hline MONI - PULO & 0.0037 & 0.0011 & 0.00785 & 0.00674 & 0.85865 & 4.28040 & 0.02886 \\
\hline CONSOLIDATED OIL & 0.0007 & 0.0002 & 0.00246 & 0.00225 & 0.91467 & 4.55965 & 0.01026 \\
\hline POOCN & 0.0810 & 0.0243 & 0.01504 & -0.00926 & -0.61536 & -3.06755 & 0.02839 \\
\hline Summation & 5.6257 & 1.6877 & 2.2 & 0.51229 & & & 0.59466 \\
\hline
\end{tabular}
their penalty price and Revenue from the template below.

Table 1. Template for Domestic Gas Supply Deficiency, Penalty Price and Revenue.

Analysis of table 1 indicates that this model provides an incentive to companies that close the gas deficit gap by reducing their penalty price and revenue. Therefore it serves as direct incentives to companies who meet with their DGSO.

\subsection{The Effect of the DGSO Deficit on the Penalty Appreciation Value}

The Penalty Appreciation Value (PAV) is heavily dependent on the difference between the gas supplied and 
actual domestic gas requirement. The Penalty Appreciation Value is the factor determining the penalty price which also directly affects the penalty revenue and the higher the PAV, the higher the Penalty Price and Revenue.

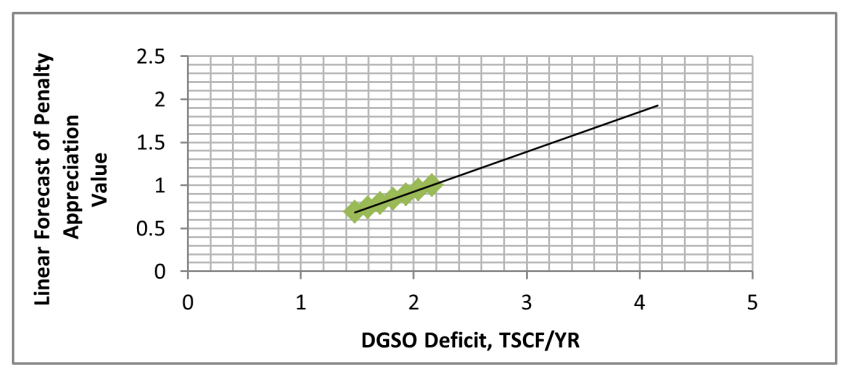

Figure 1. The effect of DGSO Deficit on the Penalty Appreciation Value.

The linear forecast of the Penalty Appreciation Value over the DGSO Deficit have shown an increase; implying that operators should work toward minimizing the gas deficit.

\subsection{The Impact of the Gas Flare Penalty on the Revenue}

Operating companies might choose to flare this gas meant for use as the domestic gas supply obligation because the cost of processing of this gas may be enormous and decide to pay penalty for not meeting with the domestic supply obligation. But at the same time these operating companies will be paying penalty as a result of flare. The sum of these penalties will determine if it is economical to pay the penalty or to process this gas. Government has an arbitrary flare price which is based on the price of gas at Henry Hub with the exception of the cost of processing this gas. This project developed a model based on the gas produced, utilised, flare, domestic gas requirement and the aggregate price of gas produced which is mathematical displayed in equation 22 and 24 . The template below shows the impact of the gas flare penalty model on the revenue.

Table 2. Template for the impact of the gas flare penalty on the Revenue.

\begin{tabular}{|c|c|c|c|c|}
\hline Company & Gas Produced, $(\mathrm{TCF} / \mathrm{yr}), P_{n}$ & Flared, TCF/yr), $\boldsymbol{F}_{\boldsymbol{n}}$ & $\begin{array}{l}\text { Domestic gas supplied, } D_{n_{i}} \\
(\mathrm{TCF} / \mathrm{yr})\end{array}$ & $\begin{array}{l}\text { Domestic gas requirement, } D=2 \text {. } \\
\text { (TCF/yr) }\end{array}$ \\
\hline SPDC & 2.2740 & 2.167 & 0.6822 & 0.914126 \\
\hline MPNU & 0.0051 & 0.003 & 0.0015 & 0.156669 \\
\hline NAOC & 1.0375 & 0.585 & 0.3112 & 0.312125 \\
\hline TOTAL/ELF & 0.9620 & 0.417 & 0.2886 & 0.279988 \\
\hline ADDAX & 0.2260 & 0.218 & 0.0678 & 0.046786 \\
\hline NPDC/AENR & 0.0453 & 0.044 & 0.0135 & 0.015558 \\
\hline SNEPCO & 0.1404 & 0.014 & 0.0421 & 0.071956 \\
\hline MONI - PULO & 0.0037 & 0.003 & 0.0011 & 0.007853 \\
\hline CONSOLIDATED OIL & 0.0007 & 0.000 & 0.0002 & 0.002461 \\
\hline POOCN & 0.0810 & 0.077 & 0.0243 & 0.015043 \\
\hline OTHERS & 0.0720 & 0 & 0.0216 & 0.075938 \\
\hline Summation & 5.6257 & 4.135 & 1.6877 & 2.2 \\
\hline
\end{tabular}

Table 2. Continued.

\begin{tabular}{|c|c|c|c|c|}
\hline Company & $\begin{array}{l}\text { Gas Deficit } D_{n}-D_{I} \text {, } \\
(\mathrm{TCF} / \mathrm{yr})\end{array}$ & $\begin{array}{l}\text { Flare Penalty } \\
\text { depreciation Value, }\left(\frac{F_{n}}{P_{n}}\right)\end{array}$ & $\begin{array}{l}\text { Flare Penalty Price, } \\
(\$ / T S C F), K_{F P_{n}}=\operatorname{KA}\left(\frac{F_{n}}{P_{n}}\right)\end{array}$ & $\begin{array}{l}\text { Flare Penalty Revenue, (S/yr), } \\
K_{F P_{n}}\left(D_{n}-D_{n_{i}}\right)\end{array}$ \\
\hline SPDC & 0.2319 & 0.9529 & 4.750437 & 1.1017 \\
\hline MPNU & 0.1551 & 0.6274 & 3.127843 & 0.4852 \\
\hline CNL & 0.0680 & 0.7763 & 3.870102 & 0.2635 \\
\hline NAOC & 0.0008 & 0.5638 & 2.810819 & $2.4 \mathrm{E}-03$ \\
\hline TOTAL/ELF & -0.0086 & 0.4339 & 2.163448 & -0.0186 \\
\hline ADDAX & -0.0210 & 0.9676 & 4.823980 & -0.1013 \\
\hline SNEPCO & 0.0298 & 0.1011 & 0.504180 & 0.0150 \\
\hline MONI - PULO & 0.0067 & 0.8108 & 4.041891 & 0.0272 \\
\hline CONSOLIDATED OIL & 0.0022 & 1 & 4.985000 & 0.0112 \\
\hline POOCN & -0.0092 & 0.9506 & 4.738827 & -0.0438 \\
\hline OTHERS & 0.0543 & 0 & 0 & 0 \\
\hline Summation & 0.5122 & 0.7350 & 3.664072 & 1.8770 \\
\hline
\end{tabular}

The summary of the table 2 shows that the gas deficit and flare penalty price has a direct impact on the flare penalty. Also that the revenue accruable is highly appreciative and this model should be commended in the sense that it is dynamic and sensitive in giving incentives to operators that has done well in achieving its domestic gas obligation. Under the same consideration, the total revenue accruable from flare is $\$ 1.877 \mathrm{~B} / \mathrm{Yr}$ which is higher than the total revenue accruable from DGSO deficit which is $\$ 0.595 \mathrm{~B} / \mathrm{Yr}$.
Therefore, companies should do everything possible not to incur this liability.

\subsection{DGSO and Flare Revenue Analysis}

One of the duties of an aggregator is to serve as an escrow management between the gas producers and consumers; and also to determine revenue accrue from gas allocation. The question the operating company's petroleum economics will keep on asking is that is it economical to gear all energy in 
meeting with their supply obligation or to flare. The table below shall run comparative analysis of the different accrue

from different situations.

Table 3. Revenue Comparisons.

\begin{tabular}{|c|c|c|c|c|}
\hline Company & $\begin{array}{l}\text { DGSO Penalty } \\
\text { Revenue, } R_{P n} . \$ B / Y r\end{array}$ & $\begin{array}{l}\text { Flare Penalty Revenue, } \\
R_{F P n} \$ \mathrm{~B} / \mathrm{Yr}\end{array}$ & $\begin{array}{l}\text { Revenue from Domestic Gas } \\
\text { Supplied, Rni, \$B/Yr }\end{array}$ & $\begin{array}{l}\text { Sum of Revenue (from Flare, } \\
\text { DGSO and DGS), } R_{A A} \$ B / Y r\end{array}$ \\
\hline SPDC & 0.2933 & 1.1017 & 3.4007 & 4.7958 \\
\hline MPNU & 0.7658 & 0.4852 & 0.0076 & 1.2586 \\
\hline CNL & 0.0766 & 0.2635 & 1.1634 & 1.5037 \\
\hline NAOC & $1.20 \mathrm{E}-05$ & $2.40 \mathrm{E}-03$ & 1.551 & $1.50 \mathrm{E}+00$ \\
\hline TOTAL/ELF & 0.0013 & -0.018 & 1.4386 & 1.4213 \\
\hline ADDAX & 0.047 & -0.101 & 0.3379 & 0.2836 \\
\hline NPDC/AENR & 0.0012 & 0.0096 & 0.0677 & 0.0786 \\
\hline SNEPCO & 0.0616 & 0.015 & 0.2099 & 0.2866 \\
\hline MONI - PULO & 0.0288 & 0.0272 & 0.0055 & 0.0616 \\
\hline $\begin{array}{l}\text { CONSOLIDATED } \\
\text { OIL }\end{array}$ & 0.0102 & 0.0112 & 0.001 & 0.0225 \\
\hline POOCN & 0.0283 & -0.043 & 0.1211 & 0.1056 \\
\hline OTHERS & 0.1938 & 0 & 0.1076 & 0.3015 \\
\hline Summation & 2.4717 & 1.877 & 8.4132 & 10.884 \\
\hline
\end{tabular}

Table 3. Continued.

\begin{tabular}{lllll}
\hline Company & $\begin{array}{l}\text { Domestic Gas Requirement } \\
\text { Revenue, Rn, \$B/Yr }\end{array}$ & $\begin{array}{l}\text { Existing Flare penalty } \\
\text { price, @ \$3.5 }\end{array}$ & $\begin{array}{l}\text { Flare Penalty Revenue, } \\
\text { @ \$3.5 }\end{array}$ & $\begin{array}{l}\text { Sum of Revenue (DGSO, } \\
\text { Flare and DGS), @ \$3.5 }\end{array}$ \\
\hline SPDC & 4.55691 & 3.5 & 0.81174 & 4.50583 \\
MPNU & 0.78099 & 3.5 & 0.54298 & 0.84394 \\
CNL & 1.50295 & 3.5 & 0.23833 & 1.69516 \\
NAOC & 1.55594 & 3.5 & 0.00306 & 1.84797 \\
TOTAL/ELF & 1.39574 & 3.5 & -0.0301 & 1.70186 \\
ADDAX & 0.23322 & 3.5 & -0.0735 & 0.55776 \\
NPDC/AENR & 0.07755 & 3.5 & 0.0068 & 0.36796 \\
SNEPCO & 0.3587 & 3.5 & 0.10442 & 0.60772 \\
MONI-PULO & 0.03914 & 3.5 & 0.0236 & 0.32246 \\
CONSOLIDATED & 0.01226 & 3.5 & 0.00787 & 0.30225 \\
OIL & 0.07499 & 3.5 & -0.0324 & 0.38206 \\
POOCN & 0.37855 & 3.5 & 0.19018 & 0.59119 \\
OTHERS & 10.967 & & 1.79301 & 10.4995 \\
Summation & & &
\end{tabular}

Some company's flare penalty tends negative signifying that there was surplus in their supply instead of deficit and they were paid for supplying surplus gas in other to close up gas deficit gas.

The knowledge of the total revenue accruable from not obliging government request for the supply of a reasonable amount of gas to the domestic market is crucial to the company's petroleum economist to enhance their decision taking in choosing between alternatives.

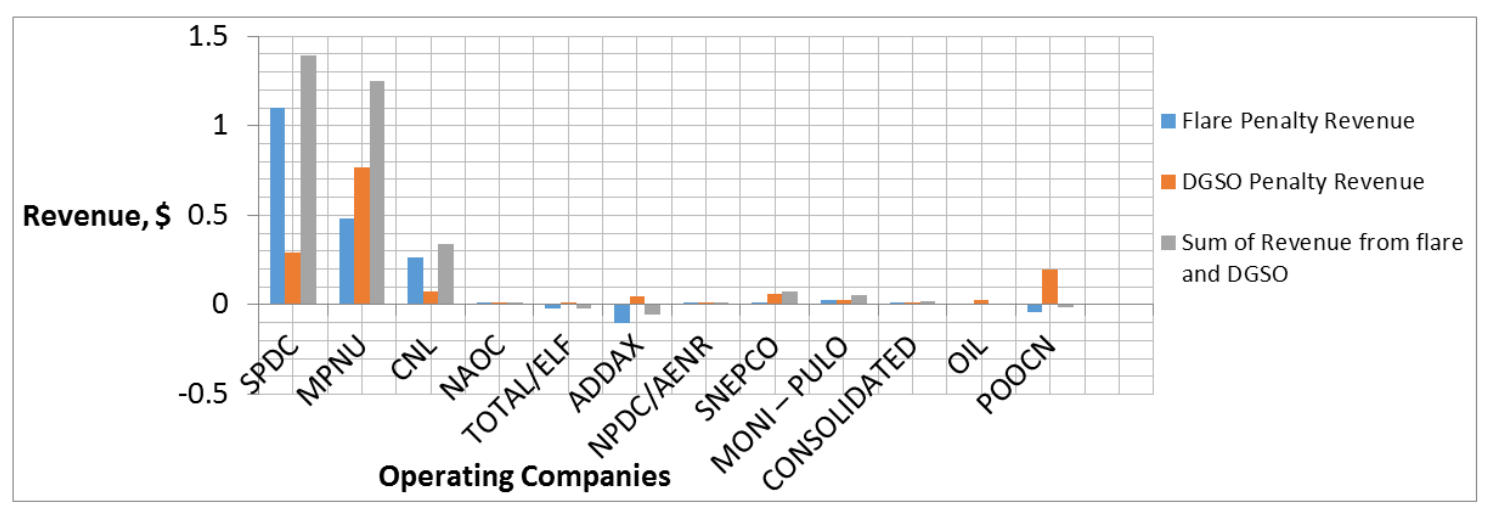

Figure 2. Comparison between the revenue from Flare, DGSO and sum (Flare and DGSO) Revenue for the Operating Companies.

From figure 2, it could be seen that SPDC is paying more than any other companies; this is because they are far behind in meeting up with the obligation and they flare more.

What you flare, supply at flare price determine the flare penalty Revenue; what you supply and at DGSO Penalty Revenue. Therefore operating companies has to be careful in altering these parameters.

The sensitivity analysis of the sum of revenues (Flare, DGSO and DGS) and the revenue from the domestic gas requirement act as an advisory tool to all stakeholders in knowing the revenue that will come adhering to any dimension. 


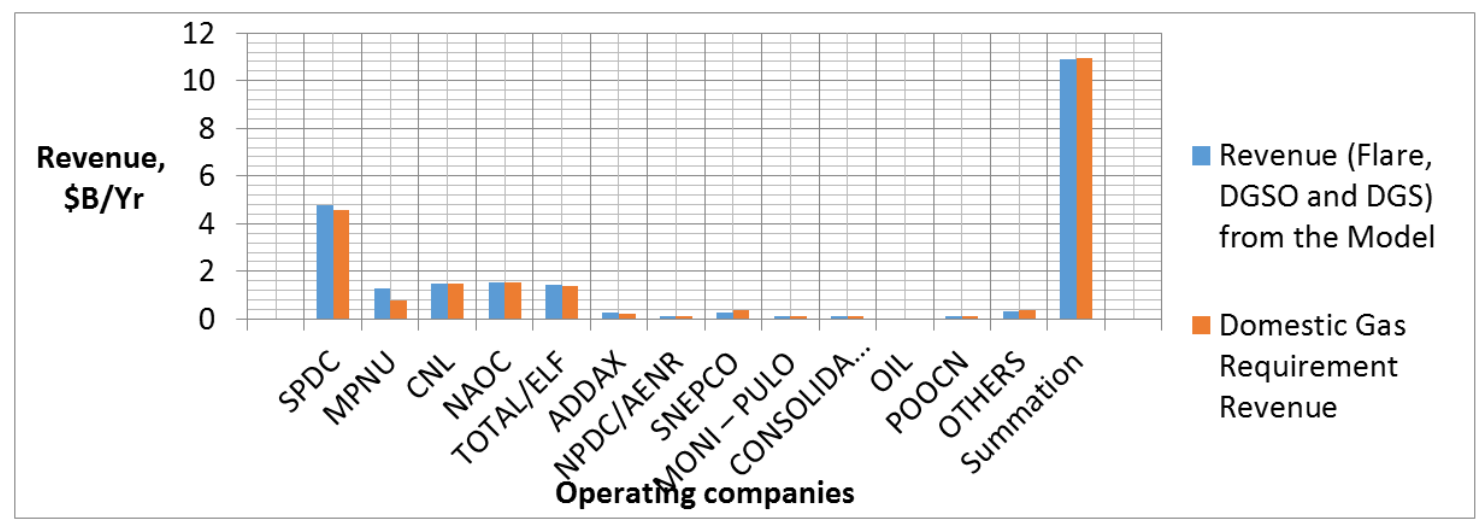

Figure 3. Comparison between the revenue from Flare, DGSO and sum of Revenue (flare and DGSO for the Operating Companies.

Figure 3 shows that company like MPNU, SPDC it is clearly better for them to meet up with the domestic gas requirement revenue than not to; because they will be paying higher if they consider other wise. While companies like SNEPCO and Others can choose to walk at this pace and still remain in business.

The figure below depicts the different revenue accrues and also portray revenue comparisons at government flare price of $\$ 3.5 \mathrm{~B} / \mathrm{TSCF}$ and the model revenue.

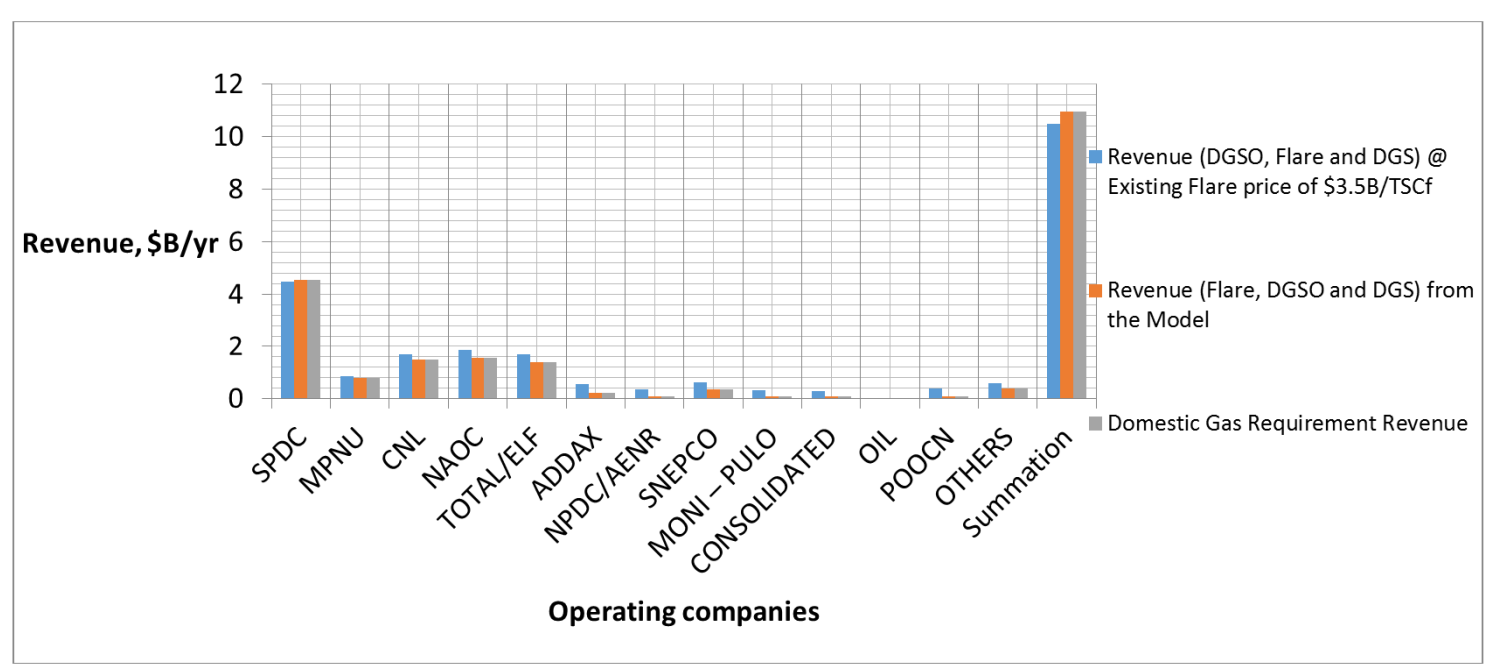

Figure 4. Comparison between the revenue @ existing flare price of \$3.5B/TSCF, Revenue @ model flare price and Revenue for Domestic Requirement for the Operating Companies.

At existing flare price, SPDC where within the boundary stipulated by the Domestic Gas Requirement Revenue and most of the other operating companies where outside the boundary; yet their total revenue were within the boundary. The significant of this is that SPDC contributing more than 55 percent of the total contributory requirement, is encourage maintaining their pace of faring with a bigger loss in their final revenue. If the model provided by this project is adopted SPDC particularly has to mend their ways and it will lead to greater profit recovery.

\section{Conclusion}

This work has determined the revenue accruable from the distribution and utilisation of gas domestically in Nigeria. The model serves as guide in decision making both to government and gas producers of the extent of financial returns realisable from the gas resource utilised in-country.
Many gas projects with drives for domestic development have been suggested. With a large market potential and an appropriate revenue model developed, Nigeria huge natural gas reserve translates to great economic growth for Nigeria. The government should strictly implement and uphold the domestic gas supply obligation to encourage the development of local gas projects and in turn create visible growth and employment opportunities in Nigeria.

\section{References}

[1] Nigerian Energy Support Program (NESP). 2015. The Nigerian Energy Sector, second edition.

[2] Franklin, U. (2013). Maximizing Africa's Gas Resources. Presented at the PWC Africa Oil and Gas Leadership Conference, Lagos, Nigeria. 
[3] Ogwo A. E, PetroGas Ltd, (2010), "Instruments for the Implementation of Domestic Gas Supply Obligation" A paper presented at Gas Stakeholders Forum in Lagos, 24th February.

[4] Okotie, S. and Ikporo, B. 2014. Utilization of Nigerian Precious Resource in the Niger Delta Region for the Benefit of the Ecosystem. International Journal of Engineering and Technology 4 (8): 488 - 498.

[5] Emejulu, O, FUTO Consult Nigeria Ltd, (2009), "Development of Gas Aggregation and Allocation Models in the Domestic Sector of the Economy" A paper presented at Gas Stakeholders Forum in Abuja, 23th March.

[6] Okparaojiaku, O. C, DPR Nigeria (2008), "Domestic Gas Supply Obligation Status" A paper presented at Gas Stakeholders Forum in Lagos, $6^{\text {th }}$ May.

[7] Ogwo, U. J. O, DPR Nigeria, (2008), “A Survey of Existing Gas Prices and Tariff Models in Nigeria" A paper presented at Gas Stakeholders Forum in Abuja, 26th November.

[8] Ehirim O. Emmanuel, Falola Ajibola Yusuf \& Ngutsav Sesugh Caleb (2018). Towards Effective Domestic Natural Gas Utilization in Nigeria. International Journal of Engineering and Modern Technology ISSN 2504-8856 Vol. 4 No. 32018.
[9] Ogwo, U. J. O, DPR Nigeria, (2007), "Equivalent Gas Pricing Model" SPE 111897, presented at 31st Nigerian Annual International Conference and Exhibition held in Abuja, Nigeria, 6rd -8 th August.

[10] David, O. I. (2008). The Nigerian Master Gas Plan- Investor Road Show. Nigerian National Petroleum Company (NNPC).

[11] Okerie, G. A, (2009), "Economic Sustainability of Gas for domestic growth" publication on Oil and Gas Journal (OGJ), 16th February.

[12] Adegoke, A. A. (2006), "Integrated GTL Power-Generation Technology: The Optimal Solution to Natural Gas Exploitation in Nigeria" SPE 105966, presented at 30th Nigerian Annual International Conference and Exhibition held in Abuja, Nigeria, 3rd - 4th August.

[13] Kehinde, A. (2016). Strategy for the Development of the Petrochemical Industry in Nigeria. Lagos, Nigeria.

[14] Akpan, S. E. (2009). Production and Utilization of Natural Gas Resources in Nigeria. Presented at + the NAICE, Abuja, Nigeria, 3-5 August. SPE-128356.

[15] Texas Comptroller of Public Accounts (TCPA), Q. 2008. Liquefied Petroleum Gas (LPG). The Energy Report. 